\title{
Different doses of methamphetamine alter long-term potentiation, level of BDNF and neuronal apoptosis in the hippocampus of reinstated rats
}

\author{
Siamak Shahidi ${ }^{1} \cdot$ Alireza Komaki $^{1} \cdot$ Reihaneh Sadeghian $^{1,2}\left[\right.$ [D Sara Soleimani Asl ${ }^{3}$
}

Received: 28 September 2018 / Accepted: 5 January 2019 / Published online: 24 January 2019

(C) The Physiological Society of Japan and Springer Japan KK, part of Springer Nature 2019

\begin{abstract}
Methamphetamine (METH) is a psychostimulant. The precise mechanisms of its effects remain unknown and current relapse treatments have low efficacy. However, brain-derived neurotrophic factor (BDNF) and neuronal plasticity are essential contributors, despite paradoxical reports and a lack of comprehensive studies. Therefore, we investigated the effects of different doses of METH on long-term potentiation (LTP), BDNF expression and neuronal apoptosis in the hippocampus of reinstated rats. Rats were injected intraperitoneally with METH $(1,5$, or $10 \mathrm{mg} / \mathrm{kg})$ or saline, and trained in a conditioned place preference paradigm. Following implementation of the reinstatement model, electrophysiology, western blotting and TUNEL assay were performed to assess behavior, LTP components, BDNF expression, and neuronal apoptosis, respectively. The results demonstrated that the preference scores, population spike amplitude and BDNF expression markedly decreased in the METH $(10 \mathrm{mg} / \mathrm{kg})$ group compared with the other groups. In contrast, METH $(5 \mathrm{mg} / \mathrm{kg})$ significantly increased these factors more than the control group. There was no change in variables between METH $(1 \mathrm{mg} / \mathrm{kg})$ and the control group. Also, apoptosis of the hippocampus was increased in the METH $(10 \mathrm{mg} / \mathrm{kg})$ group compared with the METH $(5 \mathrm{mg} / \mathrm{kg})$ group. These results suggest that alterations in synaptic plasticity, expression of BDNF and neuronal apoptosis in the hippocampus has a vital role in the context-induced reinstatement of METH seeking.
\end{abstract}

Keywords Reinstatement · Conditioned place preference $\cdot$ Long-term potentiation · Brain derived neurotrophic factor . Neuronal apoptosis $\cdot$ Methamphetamine

\section{Introduction}

Relapse of drug use following a prolonged period of drug cessation is a key barrier to addiction treatment $[1,2]$ and is an important characteristic of METH users [3]. However, there are currently no United States Food and Drug Administration (FDA)-approved pharmacotherapies for treatment of METH addiction [4]. Successful relapse prevention must

Reihaneh Sadeghian

re.sadeghian1414@gmail.com

1 Neurophysiology Research Center, Hamadan University of Medical Sciences, Hamadan, Iran

2 Medical Toxicology and Drug Abuse Research Center, Birjand University of Medical Sciences, Birjand, Iran

3 Anatomy Departments, School of Medicine, Hamadan University of Medical Sciences, Hamadan, Iran be based on an understanding of the neurobiological mechanisms of drug relapse [5].

To explore the neurobiological mechanisms of this complex behavioral phenomenon, in vivo models have been utilized in combination with functional, neurochemical, and electrophysiological techniques $[5,6]$. The drug reinstatement procedure in rats is a pre-clinical model of reinstatement in humans [7]; rats are trained using a conditioned place preference (CPP) paradigm that includes re-exposure to environmental contexts paired with a drug [8].

Emerging evidence reveals that activation of hippocampal glutamate receptors is directly implicated in reinstatement of psychostimulant seeking $[9,10]$, which glutamate receptors are interplay with changes in synaptic plasticity [11]. Hippocampal synaptic plasticity is bi-directionally modulated by psychostimulant self-administration [12]. Thus, the hippocampus is critical to studying the potential rewarding properties of METH and memory [13-16] and the contributions to reinstatement of psychostimulant seeking behavior 
[17]. Furthermore, inactivation of hippocampal outputs attenuates psychostimulant seeking associative cues [18, 19]. Additionally, developmental disruption of hippocampal connectivity increases psychostimulant self-administration [20].

Drug-induced changes in serum brain-derived neurotrophic factor (BDNF) in the cortex and hippocampus have been observed in METH users [21]. However, the source of BDNF changes and the relevance of these changes to the onset and maintenance of addiction have not been elucidated [22]. Reports on the role of psychostimulant administration on BDNF are often contradictory [23, 24]. Also, there is evidence that BDNF is a critical regulator of the late protein synthesis-dependent stage of LTP neurotransmitter release [25], thereby promoting LTP [26]. Additionally, BDNF is essential to regulation of activity-dependent pre-synaptic vesicle cycling, which is dependent on $\mathrm{N}$-methyl $\mathrm{D}$-aspartate (NMDA) receptor activation in cultured neocortical neurons from BDNF-knockout mice [27]. Furthermore, increasing of BDNF is associated with enhancing of NMDA expression and intracellular calcium concentrations [28, 29], thereby promoting long-term changes to synaptic activity.

To clarify paradoxical findings regarding the effects of psychostimulants on BDNF and LTP [27, 30], and to detect the mechanism of drug reinstatement, we administered different doses of METH to reinstated rats. The understanding of the mechanisms of METH relapse could lead to therapeutic options for patients with METH addiction.

\section{Methods}

\section{Animals}

Thirty-two adult male albino Wistar rats (8 weeks of age; $220 \pm 20 \mathrm{~g}$ ) were purchased from the animal house at the Hamadan University of Medical Science. The animals were maintained in groups of four per cage in a 12-h light/dark cycle (light on 7:00 a.m. and off 7:00 p.m.) in a room with controlled temperature, and received ad libitum access to food and water. All rats were allowed to adapt to their new environment and had regular handling for at least 1 week before the start of the experiment. Animal protocols were approved by the ethics committee of the Hamadan University of Medical Sciences (IR.Umsha.REC.1394.200), and performed according to the Guide for Care and Use of laboratory animals published by the National Institute of Health, United States (NIH Publication No. 85-23, revised 1985).

\section{Drugs}

METH (Drug Control Headquarters of the Police, Iran) was dissolved in saline and prepared fresh every day for intraperitoneal injection. Urethane was purchased from
Sigma-Aldrich (Germany). Anti-BDNF monoclonal antibody, horseradish peroxidase (HRP), the Western Blotting Substrate Kit, and $\beta$-actin antibodies were purchased from Abcam (Cambridge, UK).

\section{Apparatus for place conditioning and behavioral measurements}

The CPP apparatus was made of Plexiglas which comprised 2 equal-sized chambers $(30 \mathrm{~cm} \times 30 \mathrm{~cm} \times 40 \mathrm{~cm})$ attached by a removable wall to a third section $(30 \mathrm{~cm} \times 15 \mathrm{~cm} \times 40 \mathrm{~cm})$ that served as the null compartment. The lateral compartments had white walls with black stripes in different orientations (vertical vs horizontal), differently textured floors (smooth or net-like), and different environmental cues [31, 32]. In this apparatus, rats showed no consistent preference for any of the large compartments in the pretest, which supports our unbiased CPP paradigm. CPP protocol was conducted on 23 consecutive days and included 5 different phases: preconditioning, conditioning, post-test, extinction, and reinstatement.

The reinstatement model was developed as previously described [33, 34]. Following the pretest, animals were equally and randomly assigned to receive METH $(1,5$, or $10 \mathrm{mg} / \mathrm{kg}, n=8$; as low, medium, and high doses, respectively). According to previous research, the dose-response relationship for METH in CPP was used (dose 1 [35, 36], dose5 [37-40] and dose 10 [41, 42]) for 7 consecutive days of twice daily sessions exposed to one distinct chamber, and an alternative chamber in the presence of vehicle, with this assignment remaining fixed for the duration of the experiment for a half hour. During the post-test phase and the following day (extinction phase), each rat was placed in the middle chamber of the apparatus (no injections given) for 10 min: animals were given free access to both chambers. Conditioning scores were recorded using a published formula [43]; the time spent in the METH-paired compartment was subtracted from the time spent in the saline-paired chamber. Following the test, each rat was placed in the conditioning chamber for 30 min with a different dose METH injection before the guillotine doors were lifted on the last day of extinction. The control group received saline as a vehicle group. Finally, conditioning scores were recorded on the reinstatement phase during a 10-min period [44].

\section{Electrophysiology}

Following implementation of the reinstatement model, we assessed the population spike (PS) amplitude and field excitatory postsynaptic potential (fEPSP) slope using an electrophysiological procedure $[45,46]$. Rats were anesthetized by injection of urethane $(1.5 \mathrm{~g} / \mathrm{kg}$; intraperitoneal, i.p.) and the head was placed in a stereotaxic apparatus. Two small 
holes were drilled in the skull and the bipolar stimulation and recording electrodes were positioned in the perforant pathway and the dentate gyrus (DG) based on the Paxinos and Watson Atlas [47]. After a steady state was achieved, the stimulation intensity was regulated to evoke approximately $80 \%$ of the maximal EPSP response and the slope of the PS amplitude, using high frequency stimuli (HFS) protocols of $400 \mathrm{~Hz}$ ( 10 bursts of 20 stimuli, $0.2 \mathrm{~ms}$ stimulus duration, $10 \mathrm{~s}$ interburst interval) for 5, 30, and $60 \mathrm{~min}$ after HFS [48]. Data were analyzed using Biochart software. The value of LTP was described as: LTP $=$ the value of EPSP or PS after HFS induction/the average value of EPSP or PS at baseline $\times 100 \%[49,50]$.

\section{Western blotting}

Immediately following LTP recordings, some animals were sacrificed by rapid decapitation, and the hippocampus was removed and immediately frozen in liquid $\mathrm{N}_{2}$. The western blotting method was performed as in previous study procedures [29, 51, 52].

The right frozen hippocampi were homogenized with $200 \mu \mathrm{l}$ of lysis buffer [RIPA buffer and the inhibitor cocktail 1:20] for $1 \mathrm{~h}$ and centrifuged at $12,000 \mathrm{~g}$ at $4{ }^{\circ} \mathrm{C}$ for 20 min. Protein concentration was determined with the BioRad protein assay, and $100 \mu \mathrm{g}$ of the total protein from each sample was denatured with the sample buffer $(6.205 \mathrm{mM}$ tris- $\mathrm{HCl}, 10 \%$ glycerol, $2 \%$ SDS, $0.01 \%$ bromophenol blue, and $50 \mathrm{mM} 2-\mathrm{ME}$ ) at $95^{\circ} \mathrm{C}$ for $5 \mathrm{~min}$.

The denatured proteins were separated using SDS-PAGE (10\% sodium dodecyl sulphate-polyacrylamide gel electrophoresis) and were transferred to a nitrocellulose membrane. Nonspecific binding (NSB) were blocked with 5\% nonfat dry milk (NFDM), and the membranes were probed using anti-brain-derived neurotrophic factor (BDNF) (1:500), and $\beta$-actin (1:1000) monoclonal antibodies for $2 \mathrm{~h}$, and the anti-rabbit secondary antibodies (1:5000) were conjugated to horseradish peroxidase for $1 \mathrm{~h}$. The bands were detected using 5-bromo-4-chloro-3-indolyl phosphate in the presence of nitroblue tetrazolium as a chemiluminescent substrate. Density of the band was measured through an image analysis system (UVIdoc, Houston, TX, USA). $\beta$-actin antibody was used as a normalization control.

\section{Apoptosis (TUNEL assay)}

For histological study, the brains of anesthetized rats from the electrophysiology test were fixed through perfusion with a paraformaldehyde solution. The brains were dehydrated, embedded in paraffin, and sliced into a series of coronal sections of $5 \mu \mathrm{m}$ thickness according to previous studies [47, 53].Then, sections were used for TdT-mediated dUTP end labeling (TUNEL) staining, in which DNA fragmentation and apoptosis were detected by a TUNEL Detection Kit (Abcam) following the manufacturer's instructions. After staining, the sections were analyzed under a light microscope ( $\times 400$, Olympus). An apoptotic neuron in the hippocampal cornu ammonis $1\left(\mathrm{CA}_{1}\right)$ region showed brown colored units in the nucleus.

\section{Statistical analyses}

Data were analyzed using SPSS v16 software (IBM, Armonk, USA). CPP conditioning scores, PS amplitudes, and EPSP slopes were analyzed with one- and two-way ANOVAs. A Tukey post-hoc test was used where pairwise comparisons were performed. Furthermore, BDNF protein densities and TUNEL assay were evaluated using one-way analysis of variance (ANOVA) followed by Tukey's post hoc tests for comparisons between groups. Data are expressed as means \pm standard errors of the mean (SEMs). Statistical significance was determined by $P<0.05$ for all experiments.

\section{Results}

\section{Dose effects of METH on reinstatement of METH-induced CPP}

The effects of METH (1, 5, or $10 \mathrm{mg} / \mathrm{kg}$; i.p.) on the CPP paradigm were investigated. A two-way ANOVA for behavioral test showed significant effects between groups $[F(3$, $28)=30.46, P<0.001]$, time $[F(1,32)=42.31, P<0.001]$, and their interaction $[F(3,28)=16.03, P<0.001]$.

Figure 1a shows no significant differences in conditioning scores between any METH group on the pretest (oneway ANOVA) $[F(3,28)=0.207, P=0.890]$. [Control: $29.49 \pm 6.37$, METH $(1 \mathrm{mg} / \mathrm{kg}): 30.13 \pm 9.28$, METH $(5 \mathrm{mg} /$ $\mathrm{kg}): 39.59 \pm 8.76$, METH $(10 \mathrm{mg} / \mathrm{kg}): 37.66 \pm 6.95)$. However, there were significant differences between the control (saline) and experimental groups (5, and $10 \mathrm{mg} / \mathrm{kg}$ ) conditioning scores for the reinstatement phase (day 23). Time spent in the METH-paired chamber did not differ from time spent in the saline chamber in the METH $(1 \mathrm{mg} / \mathrm{kg})$ group $(41.38 \pm 5.69)$ compared to the control group $(26.4 \pm 4.78)$. Moreover, one-way ANOVA followed by Tukey's post hoc tests revealed that conditioning score in the $5 \mathrm{mg} / \mathrm{kg}$ METH group was significantly higher than that in the other groups during a $10-\min$ period $[F(3,28)=114.81, P<0.001]$. Conditioning scores in the $10 \mathrm{mg} / \mathrm{kg}$ METH group were significantly lower than that in the $5 \mathrm{mg} / \mathrm{kg}$ METH group $(P<0.001)$. [METH $(5 \mathrm{mg} / \mathrm{kg}): 139.86 \pm 11.07, \mathrm{METH}$ $(10 \mathrm{mg} / \mathrm{kg}): 77.92 \pm 5.71]$.

Also, paired $t$-tests indicated that preference scores significantly changed on reinstatement day compared to the pretest among experimental groups (METH 5 and $10 \mathrm{mg} / \mathrm{kg}$ ): control 
Fig. 1 Effects of exposure to different doses of methamphetamine (METH) place preference on the pretest and reinstatement day in rats. There were no significant differences in conditioning scores between any METH groups with control group on the pretest $(\mathbf{a} ; n=8$ in each group). On the reinstatement day, the preference score of $10 \mathrm{mg} / \mathrm{kg}$ METH vs $5 \mathrm{mg} /$ $\mathrm{kg}$ METH group was significant $\left({ }^{\wedge} P<0.001\right)$. The preference scores of METH 5 and $10 \mathrm{mg} / \mathrm{kg}$ vs the other groups were significant $\left({ }^{* * *} P<0.001\right.$ and ${ }^{*} P<0.05$, respectively; a). Moreover, a comparison of pretest and reinstatement days in METH 5 and $10 \mathrm{mg} / \mathrm{kg}$ showed significant differences ( $\left.{ }^{\& \&} P<0.001\right)$. Also, different doses of METH did not alter the locomotor activity in comparison with the control group $(n=8$ in each group; $\mathbf{b})$
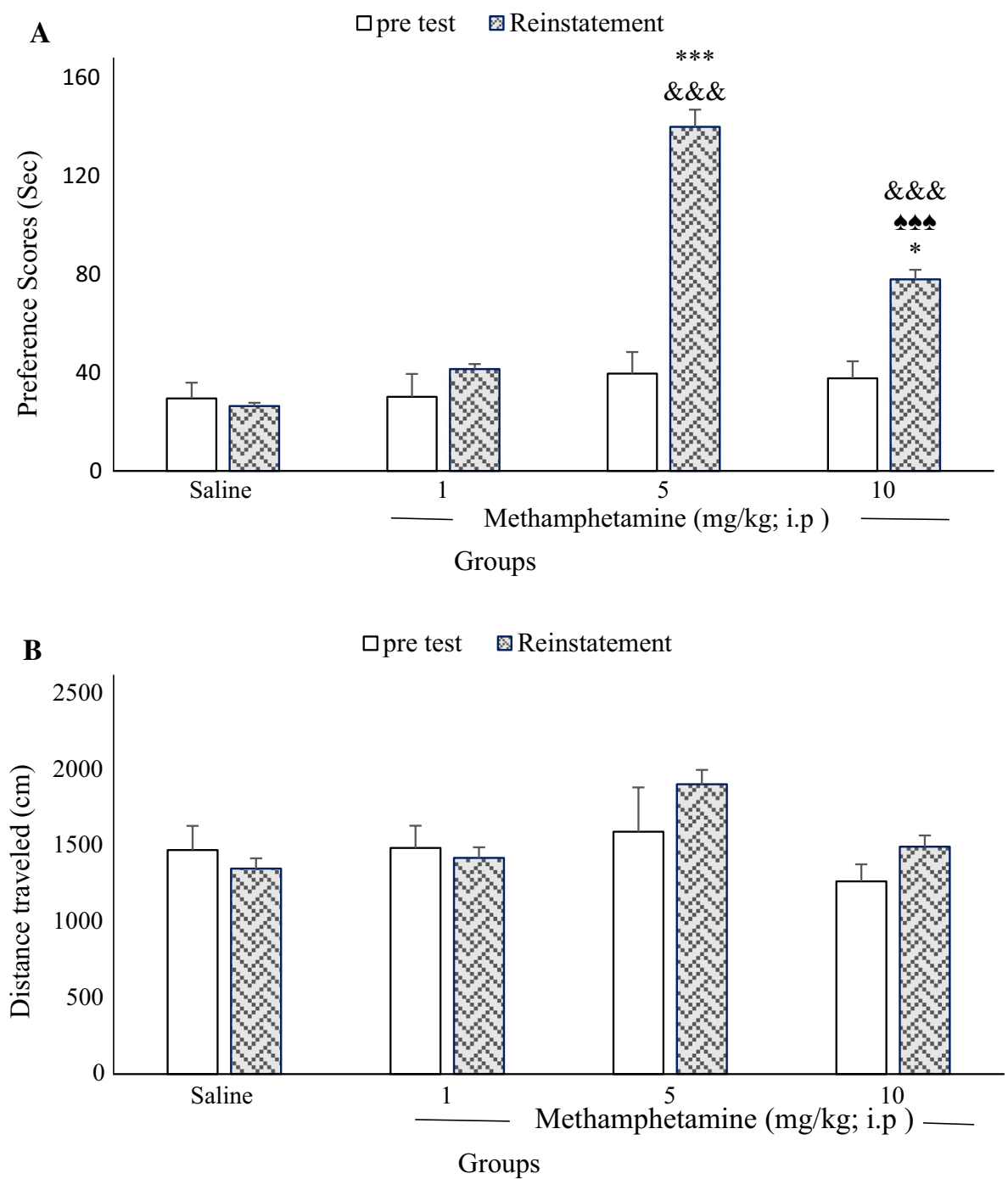

$(P=0.834)$, METH $1 \mathrm{mg} / \mathrm{kg}(P=0.260)$, METH $5 \mathrm{mg} / \mathrm{kg}$ $(P=0.000)$, METH $10 \mathrm{mg} / \mathrm{kg}(P=0.009$; Fig. 1a).

Additionally, different doses of METH did not alter the distance traveled between groups $[F(3,28)=2.1, P=0.12]$, time $[F(1,32)=0.66, P=0.42]$, or their interaction $[F(3,28)=0.9$, $P=0.45$; Fig. 1b]. Pretest [Control: 1473.10 \pm 159.04 , METH (1 mg/kg):1487.17 \pm 146.64 , METH (5 mg/ $\mathrm{kg}): 1593.37 \pm 291.59, \mathrm{METH}(10 \mathrm{mg} / \mathrm{kg}): 1266.87 \pm 112.37]$. Reinstatement [Control: $1350.87 \pm 121.99$, METH $(1 \mathrm{mg}$ / $\mathrm{kg}): 1420.53 \pm 135.20$, METH $(5 \mathrm{mg} / \mathrm{kg}): 1905.30 \pm 309.35$, METH (10 mg/kg): $1494.87 \pm 170.11]$. The reinstatement animal model was achieved after 23 days.

\section{Effects of METH administration on PS amplitudes in granular cells of the hippocampal DG in reinstated rats}

Figure $2 \mathrm{a}$ shows that the difference in the voltage between the peaks of the first positive and negative waves was defined as the amplitude of the PS. The fEPSP slope was measured as the maximum slope of the initial portion of the response. Figure $2 \mathrm{~b}$ presents an example of sample traces of responses taken before and after HFS in each group. Figure 3 illustrates the effects of METH on PS amplitudes in DG granular cell synapses on reinstatement day. The PS amplitude was significantly higher in the $5 \mathrm{mg} / \mathrm{kg}$ METH group than in all other groups. A two-way ANOVA of PS amplitude showed significant difference between groups $[F(3,28)=35.91 ; P<0.001]$, time $[F(3,96)=74.33, P<0.001]$, and their interaction $[F(9$, 84) $=17.6, P<0.001]$.

Also, one-way ANOVA indicated significant differences in the PS amplitude at $5 \mathrm{~min}[F(3,28)=37.68, P<0.001]$, $30 \mathrm{~min}[F(3,28)=32.099 ; P<0.001]$, and $60 \mathrm{~min}[F(3$, $28)=20.959 ; P<0.001]$. Furthermore, PS amplitudes were lower at all time points in rats receiving the high dose of METH $(10 \mathrm{mg} / \mathrm{kg})$ than in the other groups. One-way ANOVA revealed a significant effect of time points $(5 \mathrm{~min}$; $P<0.01)$ and (30 min; $P<0.05)$ between the $10 \mathrm{mg} / \mathrm{kg}$ 
Fig. 2 Sample traces of PS amplitude and fEPSP slope recorded prior to and after HFS in pathway perforant to dentate gyrus. Arrows indicate PS amplitude and the slope of the EPSP (a). Evoked field potentials in the DG recorded before and after HFS in all groups are shown in $(\mathbf{b})$

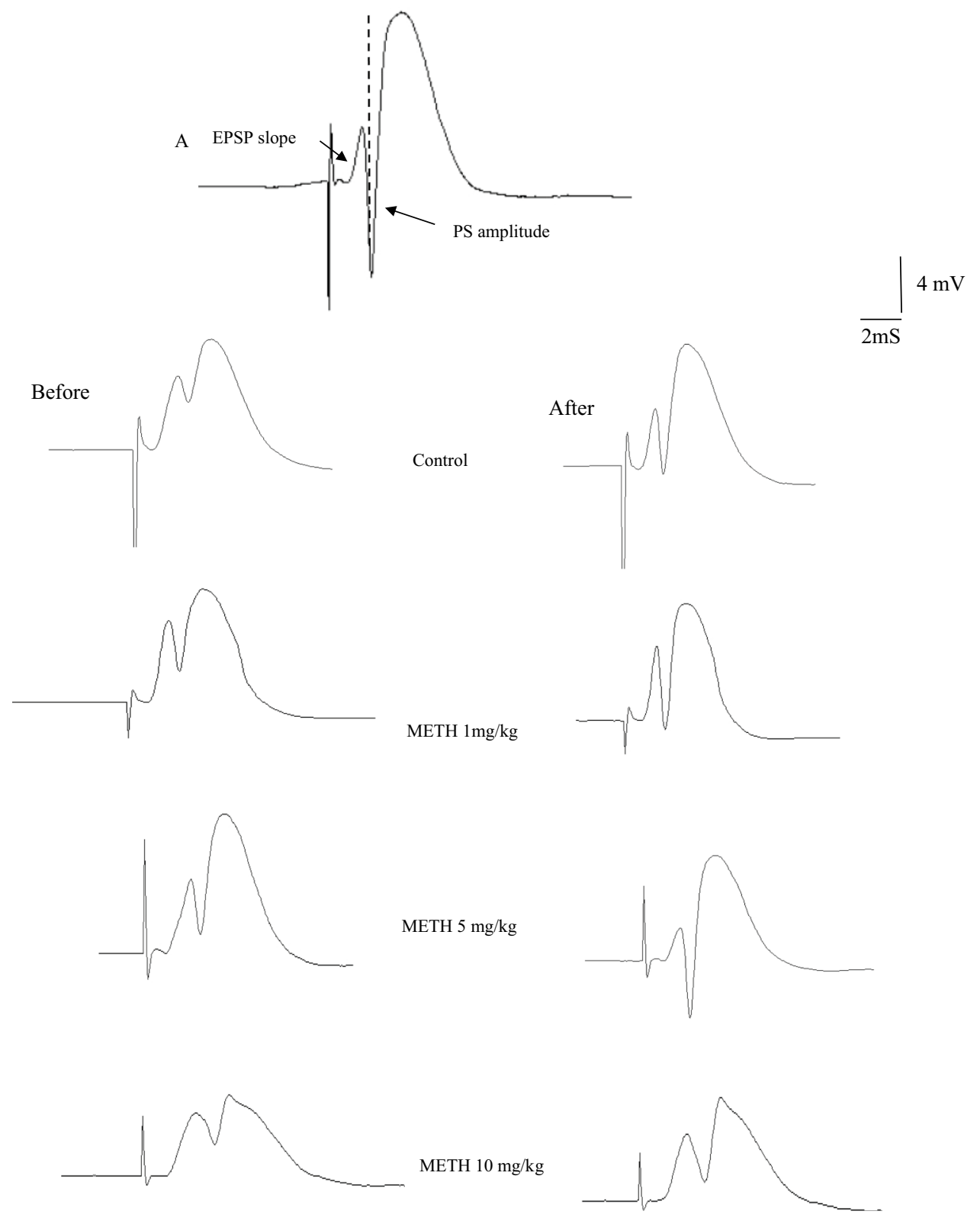

METH and $1 \mathrm{mg} / \mathrm{kg}$ METH groups; PS amplitudes in the DG granular cells were decreased in the $10 \mathrm{mg} / \mathrm{kg}$ METH group [Control (5 min: 164.24 $\pm 15.9,30 \mathrm{~min}: 174.39 \pm 11.43$, or $60 \mathrm{~min}: 161.60 \pm 12.26)$, METH $(1 \mathrm{mg} / \mathrm{kg})$ : $(5 \mathrm{~min}$ : $235.87 \pm 19.45$, $30 \mathrm{~min}: 217.46 \pm 23.94$, or $60 \mathrm{~min}$ : $214.02 \pm 28.88)$, METH $(5 \mathrm{mg} / \mathrm{kg})$ : (5 min: $390.54 \pm 28.68$, $30 \mathrm{~min}: 414.91 \pm 36.85$, or $60 \mathrm{~min}: 411.18 \pm 43.73)$, METH $(10 \mathrm{mg} / \mathrm{kg}):(5 \mathrm{~min}: 118.40 \pm 7.18,30 \mathrm{~min}: 113.80 \pm 8.35$, or 60 min: $136.79 \pm 6.52)]$.

\section{Effects of METH administration on EPSP slopes in DG granular cells of reinstated rats}

A two-way ANOVA of EPSP slope revealed significant differences between groups $[F(3,28)=3.36 ; P<0.05]$, time $[F(3,96)=8.3, P<0.001]$, and their interaction $[F(9$, $84)=2.69, P<0.01]$. After HFS, Tukey's post hoc tests revealed that the EPSP slopes in the $5 \mathrm{mg} / \mathrm{kg}$ METH group were significantly greater than for other groups at the $60-\mathrm{min}$ recording time $[F(3,28)=6.60 ; P<0.01$; Fig. 4]. There was no significant difference between groups at the 5 -min $[F(3,28)=1.470 ; P=0.244]$ or $30-\min [F(3,28)=2.471$; $P=0.082$ ] recording times [comparisons between control and other groups, $P=1.0$; METH $(1 \mathrm{mg} / \mathrm{kg})$ compared to METH $(5 \mathrm{mg} / \mathrm{kg}) P=0.248$; METH $(1 \mathrm{mg} / \mathrm{kg})$ compared to METH $(10 \mathrm{mg} / \mathrm{kg}) P=1$ ]. [Control (5 min: $110.42 \pm 5.22$, 30 min: $101.94 \pm 4.89$, or $60 \mathrm{~min}: 105.66 \pm 7.73)$, METH $(1 \mathrm{mg} / \mathrm{kg})$ : (5 min: $125.59 \pm 15.92,30 \mathrm{~min}: 102.37 \pm 11.26$, or $60 \mathrm{~min}: 103.69 \pm 8.24)$, METH $(5 \mathrm{mg} / \mathrm{kg})$ : $(5 \mathrm{~min}$ : $133.59 \pm 13.01,30 \mathrm{~min}: 124.94 \pm 7.43$, or $60 \mathrm{~min}$ : 


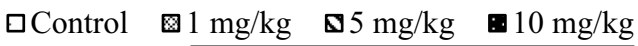 \\ Methamphetamine $(\ldots \ldots . . \mathrm{mg} / \mathrm{kg})$}

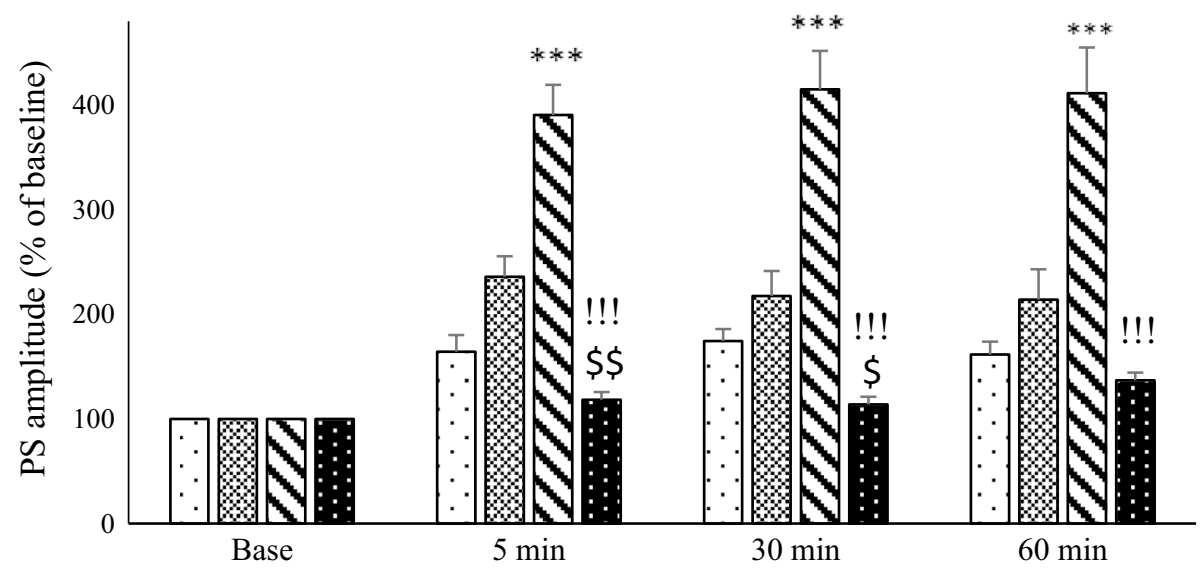

Fig. 3 The mean of the population spike (PS) amplitude in dentate gyrus granule cells following a $400-\mathrm{Hz}$ high-frequency stimulus applied to the perforant pathway. Tukey's post hoc tests indicated that the PS amplitude in the $5 \mathrm{mg} / \mathrm{kg}$ methamphetamine (METH) group was significantly higher than those in all other groups at all assessment times. Additionally, PS amplitudes were lower in the $10 \mathrm{mg} /$ $\mathrm{kg}$ METH group at all time points than in the $5 \mathrm{mg} / \mathrm{kg}$ METH group
$(P<0.001)$. One-way analysis of variance revealed significant effects at the $5 \mathrm{~min}$ and $30 \mathrm{~min}$ time points for comparisons between $10 \mathrm{mg} /$ $\mathrm{kg}$ METH, $1 \mathrm{mg} / \mathrm{kg}$ METH, and control groups; the PS amplitudes in granular cells of dentate gyrus decreased ${ }^{* * * *} P<0.0015 \mathrm{mg} / \mathrm{kg}$ METH vs control and $1 \mathrm{mg} / \mathrm{kg}$ METH group), $! ! ! P<0.01(10 \mathrm{mg} / \mathrm{kg}$ vs $5 \mathrm{mg} / \mathrm{kg} \mathrm{METH},{ }^{\$} P$ and ${ }^{\$ \$} P<0.05$ and 0.01 , respectively, $10 \mathrm{mg} /$ $\mathrm{kg}$ vs $1 \mathrm{mg} / \mathrm{kg}$ METH)
Fig. 4 Mean excitatory postsynaptic potential (EPSP) slope in dentate gyrus granule cells following $400-\mathrm{Hz}$ highfrequency stimulus applied to the perforant pathway. There were no significant differences between groups, except at $60 \mathrm{~min}$, when the EPSP slope for the $5 \mathrm{mg} / \mathrm{kg}$ methamphetamine group was significantly greater than that for the other groups $\left({ }^{* *} P<0.01, n=8\right)$

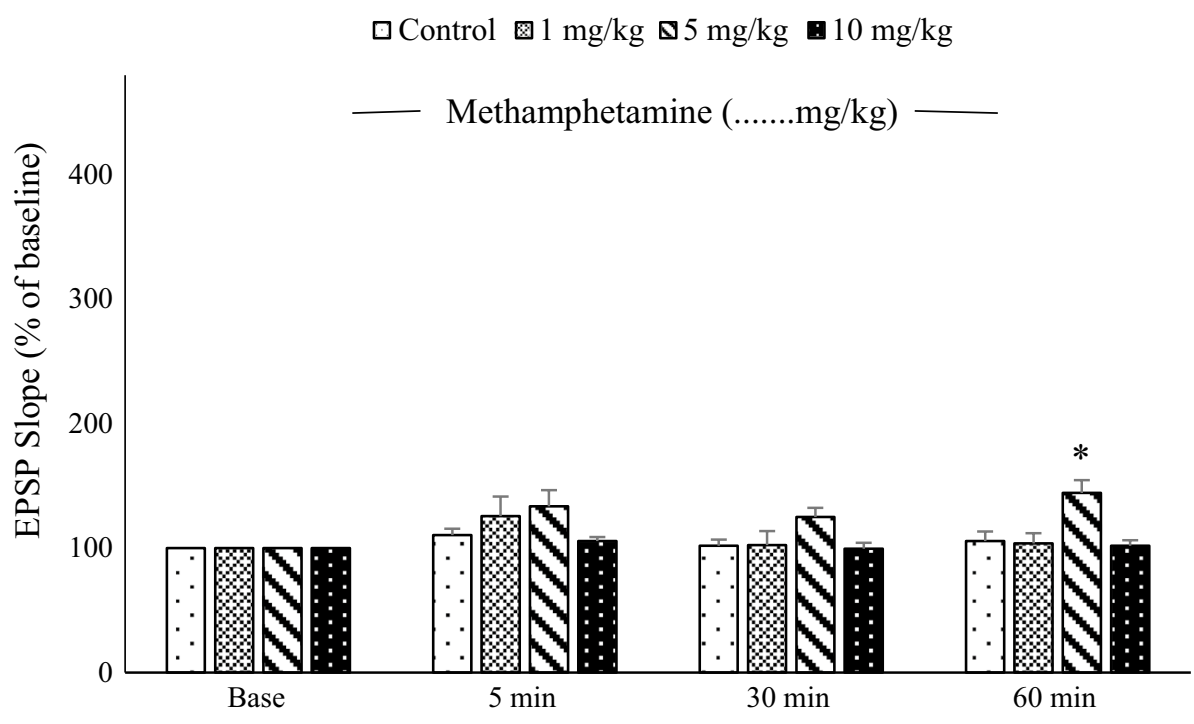

$144.40 \pm 10.16), \operatorname{METH}(10 \mathrm{mg} / \mathrm{kg}):(5 \mathrm{~min}: 105.64 \pm 3.28$, 30 min: $99.48 \pm 4.84$, or $60 \min : 101.8 \pm 4.59)]$.

\section{Effects of METH administration on BDNF expression in the hippocampus of reinstated rats}

There was a significant increase in BDNF expression in the $5 \mathrm{mg} / \mathrm{kg} \mathrm{METH}$ group compared with the control group $(P<0.01)$. BDNF expression was lower in the $10 \mathrm{mg} /$ $\mathrm{kg} \mathrm{METH}$ group than in the $5 \mathrm{mg} / \mathrm{kg} \mathrm{METH}$ and other groups $(P<0.001,0.01$ respectively; Fig. 5). [Control: $0.6833 \pm 0.038$, METH $(1 \mathrm{mg} / \mathrm{kg}): 0.71 \pm 0.036, \mathrm{METH}$ $(5 \mathrm{mg} / \mathrm{kg}): 0.93 \pm 0.036 \mathrm{METH}(10 \mathrm{mg} / \mathrm{kg}): 0.48 \pm 0.036)$.

\section{Effects of injection of METH on hippocampal $\mathrm{CA}_{1}$ cells}

Figure 6a displays a neuronal section of the $\mathrm{CA}_{1}$ hippocampus of the experimental groups. One-way ANOVA indicated a significant difference in the number of apoptotic 


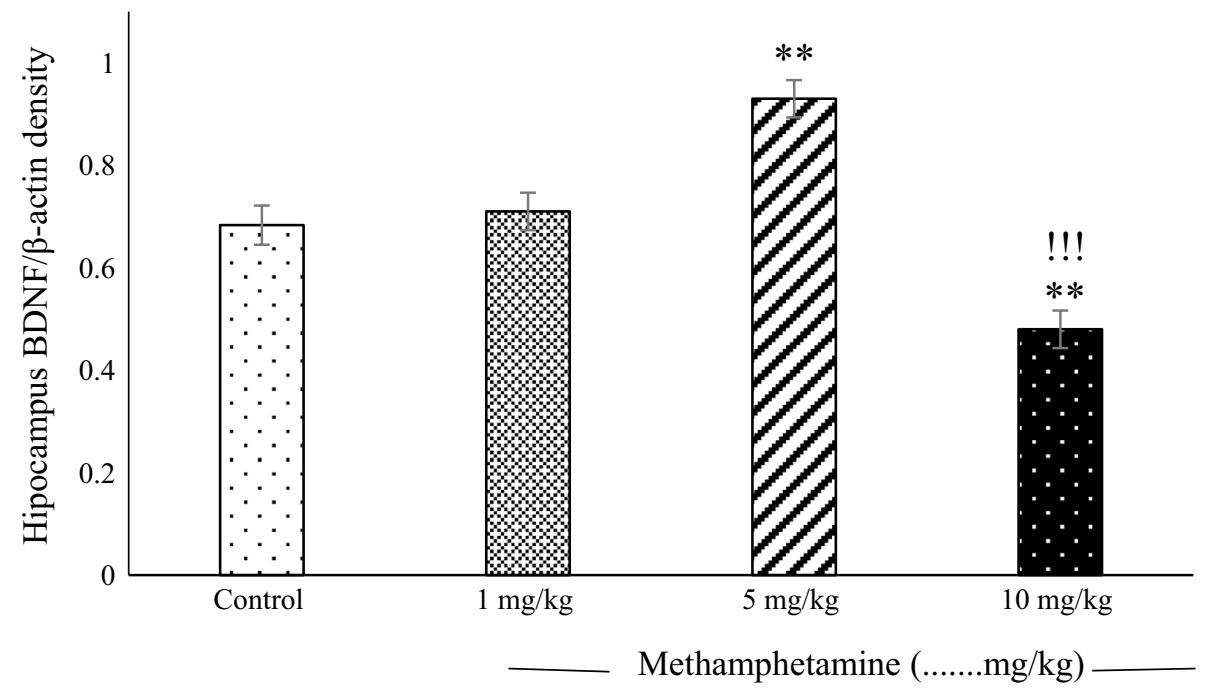

Fig. 5 The mean values ( \pm standard errors of the mean) of brainderived neurotrophic factor (BDNF) protein concentration in the hippocampus were assessed for different methamphetamine (METH) groups. There was a significant difference in higher BDNF expression for the $5 \mathrm{mg} / \mathrm{kg}$ METH group than in the control and $1 \mathrm{mg} / \mathrm{kg}$ METH groups $(P<0$. 01). BDNF expression was lower in the $10 \mathrm{mg} / \mathrm{kg}$

cells between groups $(P<0.001)$. Tukey's test showed that the brain sections of the rats in the METH group $(10 \mathrm{mg} /$ $\mathrm{kg}$ ) contained more apoptotic neurons than those in the control group $(P<0.001)$. The mean number of apoptotic neurons in the brain sections in the METH group $(5 \mathrm{mg}$ / $\mathrm{kg}$ ) was significantly decreased compared to the control rats $(P<0.01)$. There was no significant difference in apoptotic neurons counted between the control and METH $(1 \mathrm{mg} / \mathrm{kg})$ group (Fig. 6b).

\section{Discussion}

This study investigated the effects of different doses of METH on BDNF expression and long-term potentiation (LTP) and cell apoptosis in the hippocampus of reinstated rats. There were significant differences in the studied parameters between the control (saline) and moderate or high METH experimental groups ( 5 and $10 \mathrm{mg} / \mathrm{kg}$ ) during the reinstatement phase. The primary findings are as follows: (1) conditioning scores, LTP, and BDNF expression in the $5 \mathrm{mg} / \mathrm{kg}$ METH group were significantly higher than those in the other groups, (2) these parameters were significantly reduced with $10 \mathrm{mg} / \mathrm{kg}$ METH compared to $5 \mathrm{mg} / \mathrm{kg} \mathrm{METH}$, and sometimes also compared to other groups, and (3) there is an interplay between alterations in LTP and BDNF expression. (4) Intraperitoneal injection of $10 \mathrm{mg} / \mathrm{kg}$ METH caused neuronal death in the hippocampus area, while (5) METH $(5 \mathrm{mg} / \mathrm{kg})$ decreased neuronal death in this area.
METH group than in the $5 \mathrm{mg} / \mathrm{kg}$ METH group, the $1 \mathrm{mg} / \mathrm{kg}$ METH group, and the control group $(P<0.001)$. There were no differences in BDNF expression between the $1 \mathrm{mg} / \mathrm{kg}$ METH group and the control group $\left({ }^{* *} P<0.01 ; 5\right.$, and $10 \mathrm{mg} / \mathrm{kg}$ METH vs $1 \mathrm{mg} / \mathrm{kg}$ METH and control, ${ }^{! ! !} P<0.00110 \mathrm{mg} / \mathrm{kg}$ vs $5 \mathrm{mg} / \mathrm{kg}$ METH, $n=8$ )

There is evidence that neurotrophins contribute to neuronal plasticity $[54,55]$. LTP is the most widely used paradigm to study cellular and molecular events underlying neuronal plasticity $[45,56]$. Therefore, we used this paradigm in the dentate-perforant pathway of reinstated rats, and hippocampal BDNF expression was assessed using western blotting to evaluate whether BDNF contributes to drug seeking behavior interplay with LTP. Previous research has demonstrated that drug addiction behavior for psychostimulants is established and maintained via BDNF-dependent mechanisms $[57,58]$. The CPP paradigm is widely used to assess associations between drugs and the context in which they are experienced, and it is used as an animal model to assess drug reward and reinstatement [4].

In our first study, CPP conditioning scores (drug seeking behavior) and BDNF expression were compared between the control and experimental groups on the reinstatement day. Our results indicate that METH $(1 \mathrm{mg} / \mathrm{kg})$ did not produce significantly different conditioning scores or BDNF expression compared to the control group. This finding contrasts with Shen et al., who found that a lower dose of d-AMP significantly reinstated CPP, and that polymerase chain reaction for BDNF mRNA demonstrated a significant increase after reinstatement [57]. Furthermore, conditioning scores and BDNF expression in their $5 \mathrm{mg} / \mathrm{kg}$ group was significantly higher than those in the other groups. Consistent with our study, Corominas et al. found that repeated cocaine administration increases BDNF expression and enhances activity in intracellular pathways (PI3 K and MAPK/ERK) 
A
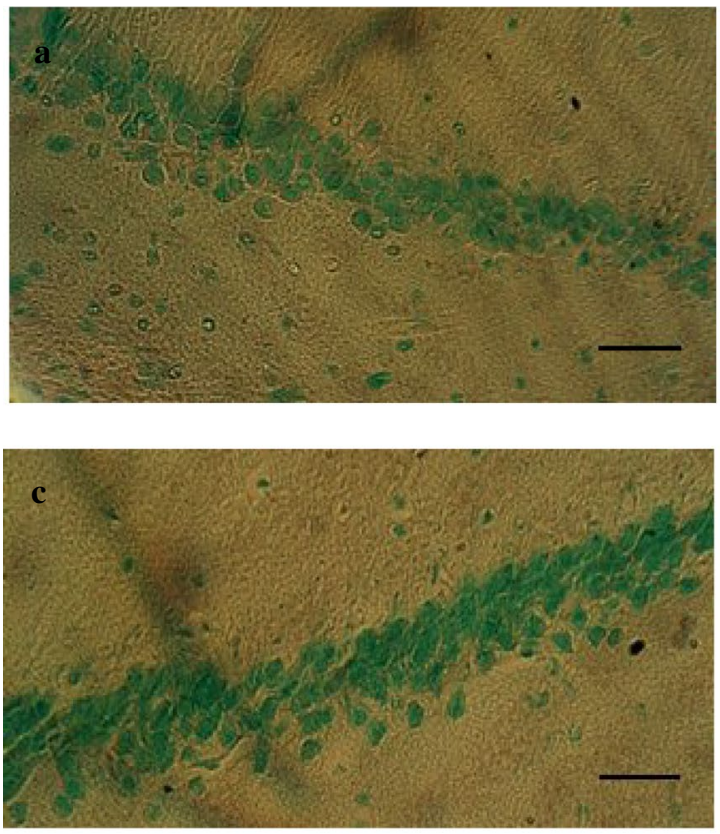

B
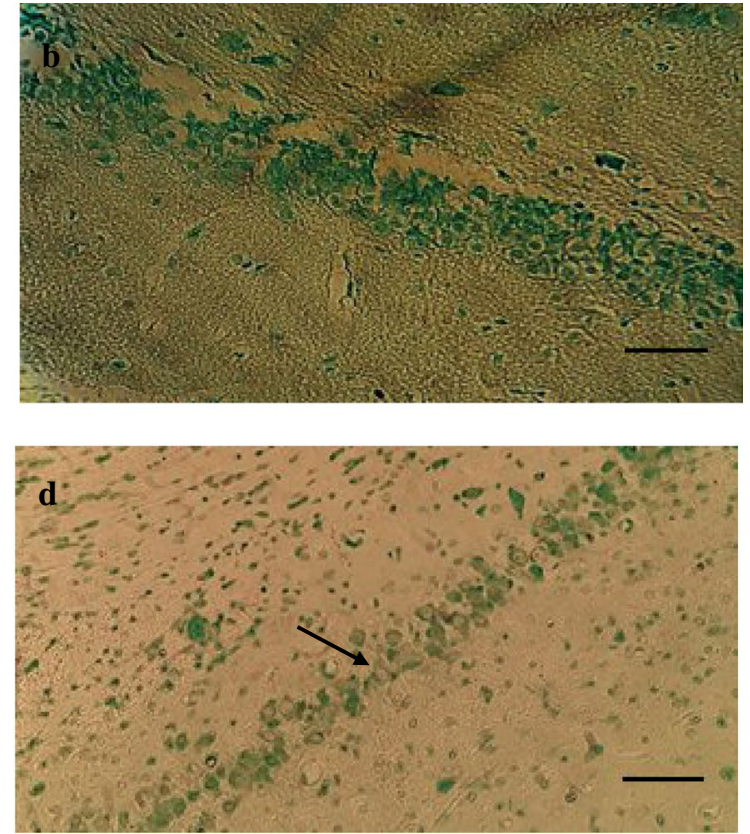

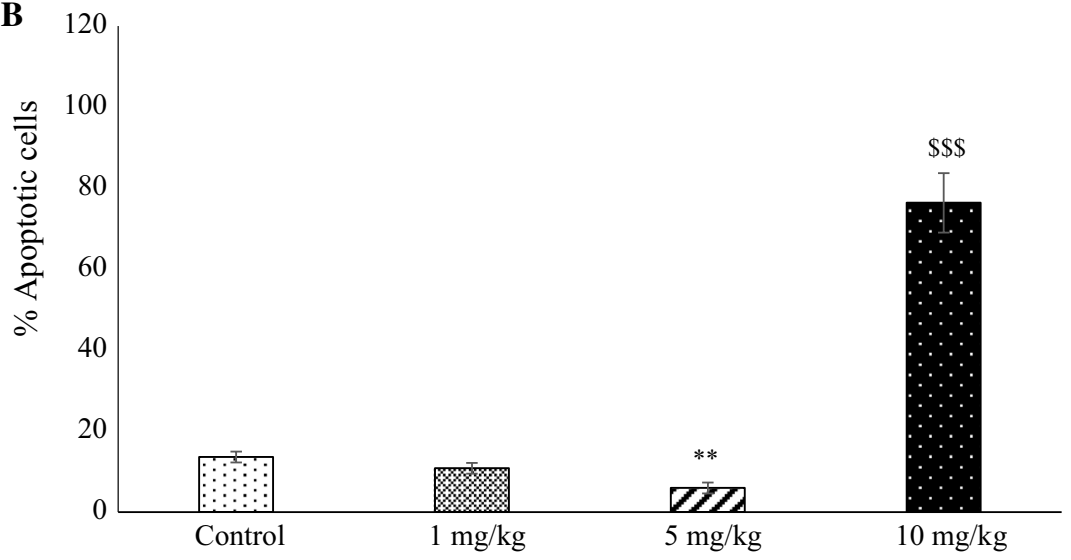

Fig. 6 Light micrographs of cell apoptosis in the hippocampal $\mathrm{CA}_{1}$ region. a Sections derived from $a$ : control; $b$ : METH $(1 \mathrm{mg} / \mathrm{kg}) ; c$ : METH $(5 \mathrm{mg} / \mathrm{kg})$; and $d$ : METH $(10 \mathrm{mg} / \mathrm{kg})$ groups stained by TUNEL. The arrow shows an apoptotic neuron. The mean percent-

in reward-related brain areas for several days following withdrawal [59]. In contrast to our results, Berglind et al. reported that exogenous intra-dmPFC infused with BDNF suppressed cocaine-seeking after $22 \mathrm{~h}$ or $6 \mathrm{~d}$ of abstinence, including during tests of cue-induced and cocaine primeinduced reinstatement [60]. However, $\mathrm{Pu}$ et al. showed the elevated BDNF expression in the ventral tegmental area after cocaine withdrawal is associated with drug craving and reinstatement [61].

Although BDNF has been proposed as a contributor to drug reward and reinstatement, the role of BDNF in drugseeking behavior may be more diverse and complex than previously thought, and these enhanced roles have not yet age of apoptotic cells was measured (b) $* * P<0.01$ as compared with the control group, ${ }^{\$ \$} P<0.001$ as compared with the METH $(5 \mathrm{mg} /$ $\mathrm{kg}$ ) group. Each column represents mean \pm SEM. Scale bar $=50 \mu \mathrm{m}$, magnification: $\times 400$

been elucidated [58, 62]. Therefore, we investigated the role of synaptic plasticity on BDNF during relapse behavior. BDNF is a central mediator of activity-dependent plasticity, through which environmental experiences such as sensory information are translated into the structure and function of neuronal networks [25]. Late-phase LTP (L-LTP) requires new protein synthesis of BDNF as a neurotransmitter modulator; as a result, connections between neurons at synapses change in strength [54]. Additionally, during bilateral communication, HFS-induced LTP also occurs, which produces a time-dependent increase in BDNF mRNA levels within dentate granule cells for approximately $30 \mathrm{~min}$, with levels returning to baseline by $4 \mathrm{~h}$ [63]. Although there is strong 
evidence for a critical role of BDNF in L-LTP and long-term memory, many issues have not been resolved [54].

The present results demonstrated that conditioning scores, LTP, and BDNF expression in the $10 \mathrm{mg} / \mathrm{kg}$ METH group were lower than those in the $5 \mathrm{mg} / \mathrm{kg}$ METH group. Also, apoptosis of hippocampus cells in the METH $(10 \mathrm{mg} / \mathrm{kg})$ rats was increased compared with METH $(5 \mathrm{mg} / \mathrm{kg})$. Comparison between medium and high doses of METH in the other studies showed that injection of moderate METH significantly increased LTP [45] and level of BDNF expression in the serum and frontal cortex [64], probably via increasing release of neurotransmitters [45]. Also, in comparison with earlier research, injection of high doses of METH, including $10 \mathrm{mg} / \mathrm{kg} /$ four times at 2-h intervals, or a single dose of $40 \mathrm{mg} / \mathrm{kg}$, led to decreased LTP in the $\mathrm{CA}_{1}$ of mouse hippocampus [27], increasing cell apoptosis [65]. These are in accordance with the present results. The high dose of METH that decreased LTP may due to increased apoptosis. Furthermore, it has been reported that a high concentration of METH reduces hippocampal LTP (maladaptive plasticity) and neurogenesis, and following it there was extended access expression of BDNF in the hippocampus which is necessary for blocking METH-induced neuronal death [66]. However, some research has focused on direct injection of BDNF into brain nuclei and its effects on search behavior [67]. A previous finding showed injection of doses of toxic METH (high dose, probably) facilitated BDNF synthesis or prevention of degradation of BDNF through dopamine and/ or glutamate receptors [68], which appears to be contrary to our result. This controversy may due to the protocol of the experiment. For example, duration and times of injections, kind of injection (ICV, I.P., SC), chronic or acute may cause contrary results. The present study is the first study in this field. Therefore, there is not enough information about the effect of high doses on BDNF reduction compared to a dose of METH $(5 \mathrm{mg} / \mathrm{kg})$. Further research may determine the reasons for these effects of different doses of METH.

It is possible that psychostimulants alter synaptic plasticity in the brain, which may partly account for their adverse effects. Previously, it was thought that psychostimulants can induce both increases and decreases in hippocampal LTP, depending on the applied concentration [30, 69]. The decrease in LTP following high concentrations of cocaine may be due to blockade of sodium and and calcium channels, or blockade of large-conductance dependent potassium channels $[12,70,71]$. Thus, we did not expect to find no effect in LTP at lower doses of METH; contrary to previous findings [27], our results demonstrate that differences in LTP did not occur in the hippocampus of the $1 \mathrm{mg} / \mathrm{kg} \mathrm{METH}$ group compared to the control group.

BDNF is implicated in long-term synaptic plasticity in the adult hippocampus, although the cellular mechanisms are not well-understood [55]. Our results suggest that LTP, and BDNF expression increased in the hippocampus of the $5 \mathrm{mg} / \mathrm{kg}$ METH group. Initially, in vitro studies indicated that exogenous BDNF promotes LTP induction by enhancing synaptic responses to tetanic stimulation in young hippocampal slices [72]. In contrast, another study demonstrated that LTP was attenuated in slices pre-treated with function-blocking BDNF antibodies or a molecular scavenger of endogenous BDNF [73].

Our result showed that METH $(5 \mathrm{mg} / \mathrm{kg})$ decreased neuronal death in the hippocampus, while METH $(10 \mathrm{mg} / \mathrm{kg})$ increased this factor. Another study showed that a single injection of METH $(40 \mathrm{mg} / \mathrm{kg})$ caused cell death in the striatum, cortex, and hippocampus [74]. Also, a single high dose of $30 \mathrm{mg} / \mathrm{kg}$ METH induced apoptosis of nearly $25 \%$ of striatal neurons [75].

\section{Conclusion}

In summary, our findings suggest that METH reinstatement affects excitatory synaptic transmission, likely via alterations in BDNF protein expression and neuronal death. METH has dose-dependent effects on BDNF expression and LTP. Additional histological and behavioral experiments related to memory, such as T-maze tests, should be conducted to elucidate the mechanisms and effects of METH on reinstatement induction. Enhanced understanding of the mechanisms of drug relapse will contribute to development of novel treatment strategies for people who wish to cease use.

Acknowledgements We thank Drug Control Headquarters of the Police, Hamadan, Iran, the vice-chancellor for Research and Technology, Hamadan University of Medical Sciences (no. 9407073722), and the Cognitive Science and Technologies Council (no. 3078), Tehran, who supported this study in the provision of equipment and supplies.

\section{Compliance with ethical standards}

Conflict of interest The authors declare that there is no conflict of interest for any of them.

Ethical approval All animal experimental procedures were performed in accordance with the guidelines for proper conduct of animal experiments issued by the Ethics Committee of the Hamadan University of Medical Sciences (IR.Umsha.REC.1394.200), and performed according to The Guide for Care and Use of Laboratory Animals published by the National Institutes of Health, United States (NIH Publication No. 85-23, revised 1985).

\section{References}

1. Bamford NS et al (2008) Repeated exposure to methamphetamine causes long-lasting presynaptic corticostriatal depression that is renormalized with drug readministration. Neuron 58(1):89-103 
2. Shahidi S, Hasanein P (2011) Behavioral effects of fatty acid amide hydrolase inhibition on morphine withdrawal symptoms. Brain Res Bull 86(1-2):118-122

3. Rogers JL, De Santis S, See RE (2008) Extended methamphetamine self-administration enhances reinstatement of drug seeking and impairs novel object recognition in rats. Psychopharmacology 199(4):615-624

4. Napier TC, Herrold AA, de Wit H (2013) Using conditioned place preference to identify relapse prevention medications. Neurosci Biobehav Rev 37:2081-2086

5. Fuchs RA et al (2008) Relapse to drug seeking following prolonged abstinence: the role of environmental stimuli. Drug Discov Today Dis Models 5(4):251-258

6. Choi S et al (2017) Noradrenergic inhibition of spinal hyperexcitation elicited by cutaneous cold stimuli in rats with oxaliplatininduced allodynia. Electrophysiol Behav Asses 67(3):431-438

7. Yahyavi-Firouz-Abadi N, See RE (2009) Anti-relapse medications: preclinical models for drug addiction treatment. Pharmacol Ther 124(2):235-247

8. Pickens CL et al (2011) Neurobiology of the incubation of drug craving. Trends Neurosci 34(8):411-420

9. Hammad AM et al (2017) Modulatory effects of ampicillin/sulbactam on glial glutamate transporters and metabotropic glutamate receptor 1 as well as reinstatement to cocaine-seeking behavior. Behav Brain Res 332:288-298

10. Siahposht-Khachaki A et al (2017) Involvement of AMPA/kainate glutamate receptor in the extinction and reinstatement of morphine-induced conditioned place preference: a behavioral and molecular study. Cell Mol Neurobiol 37(2):315-328

11. Briand LA et al (2016) Disrupting GluA2 phosphorylation potentiates reinstatement of cocaine seeking. Neuropharmacology 111:231-241

12. Thompson AM et al (2004) Modulation of long-term potentiation in the rat hippocampus following cocaine self-administration. Neuroscience 127(1):177-185

13. Keleta YB, Martinez JL (2012) Brain circuits of methamphetamine place reinforcement learning: the role of the hippocampusVTA loop. Brain Behav 2(2):128-141

14. Recinto P et al (2012) Levels of neural progenitors in the hippocampus predict memory impairment and relapse to drug seeking as a function of excessive methamphetamine self-administration. Neuropsychopharmacology 37(5):1275-1287

15. Azizi-Malekabadi $\mathrm{H}$ et al (2012) Different effects of scopolamine on learning, memory, and nitric oxide metabolite levels in hippocampal tissues of ovariectomized and sham-operated rats. Arq Neuropsiquiatr 70(6):447-452

16. Sadeghian R et al (2012) Decreased nitric oxide levels in the hippocampus may play a role in learning and memory deficits in ovariectomized rats treated by a high dose of estradiol. Arq Neuropsiquiatr 70(11):874-879

17. Ricoy UM, Martinez JL Jr (2009) Local hippocampal methamphetamine-induced reinforcement. Front Behav Neurosci 3:47

18. Rogers JL, See RE (2007) Selective inactivation of the ventral hippocampus attenuates cue-induced and cocaine-primed reinstatement of drug-seeking in rats. Neurobiol Learn Memory 87(4):688-692

19. Sun W, Rebec GV (2003) Lidocaine inactivation of ventral subiculum attenuates cocaine-seeking behavior in rats. J Neurosci 23(32):10258-10264

20. Chambers RA, Self DW (2002) Motivational responses to natural and drug rewards in rats with neonatal ventral hippocampal lesions: an animal model of dual diagnosis schizophrenia. Neuropsychopharmacology 27(6):889-905

21. Kim DJ et al (2005) High concentrations of plasma brain-derived neurotrophic factor in methamphetamine users. Neurosci Lett 388(2):112-115
22. Russo SJ et al (2009) Neurotrophic factors and structural plasticity in addiction. Neuropharmacology 56:73-82

23. Chen PH et al (2014) Serum brain-derived neurotrophic factor levels were reduced during methamphetamine early withdrawal. Addict Biol 19(3):482-485

24. Hajheidari $S$ et al (2017) Effects of prolonged abstinence from METH on the hippocampal BDNF levels, neuronal numbers and apoptosis in methamphetamine-sensitized rats. Neurosci Lett 645:80-85

25. Castren E, Antila H (2017) Neuronal plasticity and neurotrophic factors in drug responses. Mol Psychiatry 22(8):1085-1095

26. Korte $\mathrm{M}$ et al (1995) Hippocampal long-term potentiation is impaired in mice lacking brain-derived neurotrophic factor. Proc Natl Acad Sci USA 92(19):8856-8860

27. Swant J et al (2010) Methamphetamine reduces LTP and increases baseline synaptic transmission in the CA1 region of mouse hippocampus. PLoS One 5(6):e11382

28. Walz $\mathrm{C}$ et al (2006) Presynaptic plasticity in an immature neocortical network requires NMDA receptor activation and BDNF release. J Neurophysiol 96(6):3512-3516

29. da Silveira FP et al (2017) BDNF levels are increased in peripheral blood of middle-aged amateur runners with no changes on histone H4 acetylation levels. J Physiol Sci 67(6):681-687

30. Thompson AM, Swant J, Wagner JJ (2005) Cocaine-induced modulation of long-term potentiation in the CA1 region of rat hippocampus. Neuropharmacology 49(2):185-194

31. Baharlouei $\mathrm{N}$ et al (2015) Blockage of acquisition and expression of morphine-induced conditioned place preference in rats due to activation of glutamate receptors type II/III in nucleus accumbens. Pharmacol Biochem Behav 135:192-198

32. Roohi $\mathrm{N}$ et al (2014) Microinjection of the mGluR5 antagonist MTEP into the nucleus accumbens attenuates the acquisition but not expression of morphine-induced conditioned place preference in rats. Pharmacol Biochem Behav 126:109-115

33. Abulseoud OA et al (2012) Ceftriaxone upregulates the glutamate transporter in medial prefrontal cortex and blocks reinstatement of methamphetamine seeking in a condition place preference paradigm. Brain Res 1456:14-21

34. Zarepour L et al (2013) Potentiation of rewarding properties of morphine by concurrent chemical stimulation of lateral hypothalamus in rats. Pharmacol Biochem Behav 107:36-41

35. Arezoomandan R et al (2016) Administration of activated glial condition medium in the nucleus accumbens extended extinction and intensified reinstatement of methamphetamine-induced conditioned place preference. Brain Res Bull 125:106-116

36. Attarzadeh-Yazdi G, Arezoomandan R, Haghparast A (2014) Minocycline, an antibiotic with inhibitory effect on microglial activation, attenuates the maintenance and reinstatement of methamphetamine-seeking behavior in rat. Prog Neuropsychopharmacol Biol Psychiatry 53:142-148

37. Cass WA (1997) Decreases in evoked overflow of dopamine in rat striatum after neurotoxic doses of methamphetamine. J Pharmacol Exp Ther 280(1):105-113

38. Itzhak Y, Ali SF (1996) The neuronal nitric oxide synthase inhibitor, 7-nitroindazole, protects against methamphetamine-induced neurotoxicity in vivo. J Neurochem 67(4):1770-1773

39. Sim MS et al (2017) MicroRNA expression signature of methamphetamine use and addiction in the rat nucleus accumbens. Metab Brain Dis 32(6):1767-1783

40. Heysieattalab S et al (2016) Methamphetamine-induced enhancement of hippocampal long-term potentiation is modulated by NMDA and GABA receptors in the shell-accumbens. Synapse 70(8):325-335

41. Alshehri FS, Althobaiti YS, Sari Y (2017) Effects of administered ethanol and methamphetamine on glial glutamate transporters in rat striatum and hippocampus. J Mol Neurosci 61(3):343-350 
42. Bowyer JF et al (2017) Corticosterone and exogenous glucose alter blood glucose levels, neurotoxicity, and vascular toxicity produced by methamphetamine. J Neurochem 143(2):198-213

43. Vatankhah M et al (2018) AMN082-a metabotropic glutamate receptor type 7 allosteric agonist in the NAc facilitates extinction and inhibits the reinstatement of morphine-induced conditioned place preference in male rats. Brain Res Bull 140:28-33

44. Meng S et al (2014) Effect of baclofen on morphine-induced conditioned place preference, extinction, and stress-induced reinstatement in chronically stressed mice. Psychopharmacology 231(1):27-36

45. Shahidi S et al (2018) Effect of a 5-HT1D receptor agonist on the reinstatement phase of the conditioned place preference test and hippocampal long-term potentiation in methamphetamine-treated rats. Brain Res 1698:151-160

46. Shahidi S et al (2018) The effect of chronic stimulation of serotonin receptor type 7 on recognition, passive avoidance memory, hippocampal long-term potentiation, and neuronal apoptosis in the amyloid beta protein treated rat. Psychopharmacology 235(5):1513-1525

47. Hashemi-Firouzi N et al (2017) The effects of the 5-HT7 receptor on hippocampal long-term potentiation and apoptosis in a rat model of Alzheimer's disease. Brain Res Bull 135:85-91

48. Salehi I et al (2015) Effects of vitamin E on lead-induced impairments in hippocampal synaptic plasticity. Brain Res 1629:270-281

49. Karamian R et al (2015) Vitamin C reverses lead-induced deficits in hippocampal synaptic plasticity in rats. Brain Res Bull 116:7-15

50. Lashgari R et al (2008) Effects of reversible inactivation of locus coeruleus on long-term potentiation in perforant path-DG synapses in rats. Neurobiol Learn Mem 90(2):309-316

51. Rahimi A et al (2018) Sublethal concentration of $\mathrm{H} 2 \mathrm{O} 2$ enhances the protective effect of mesenchymal stem cells in rat model of spinal cord injury. Biotechnol Lett 40(3):609-615

52. Beheshti $\mathrm{F}$ et al (2019) The effects of aminoguanidine on hippocampal cytokines, amyloid beta, brain-derived neurotrophic factor, memory and oxidative stress status in chronically lipopolysaccharide-treated rats. Cytokine 113:347-355

53. Afshar $\mathrm{S}$ et al (2018) The effect of NAD-299 and TCB-2 on learning and memory, hippocampal BDNF levels and amyloid plaques in streptozotocin-induced memory deficits in male rats. Psychopharmacology 235(10):2809-2822

54. Lu Y, Christian K, Lu B (2008) BDNF: a key regulator for protein synthesis-dependent LTP and long-term memory? Neurobiol Learn Mem 89(3):312-323

55. Ying SW et al (2002) Brain-derived neurotrophic factor induces long-term potentiation in intact adult hippocampus: requirement for ERK activation coupled to CREB and upregulation of Arc synthesis. J Neurosci 22(5):1532-1540

56. Komaki A et al (2007) Effects of GABAergic inhibition on neocortical long-term potentiation in the chronically prepared rat. Neurosci Lett 422(3):181-186

57. Shen YL et al (2014) Elevated BDNF mRNA expression in the medial prefrontal cortex after d-amphetamine reinstated conditioned place preference in rats. Neuroscience 263:88-95

58. Graham DL et al (2007) Dynamic BDNF activity in nucleus accumbens with cocaine use increases self-administration and relapse. Nat Neurosci 10(8):1029-1037

59. Corominas $\mathrm{M}$ et al (2007) Brain-derived neurotrophic factor and its intracellular signaling pathways in cocaine addiction. Neuropsychobiology 55(1):2-13
60. Berglind WJ et al (2007) A BDNF infusion into the medial prefrontal cortex suppresses cocaine seeking in rats. Eur J Neurosci 26(3):757-766

61. Pu L, Liu QS, Poo MM (2006) BDNF-dependent synaptic sensitization in midbrain dopamine neurons after cocaine withdrawal. Nat Neurosci 9(5):605-607

62. Lu L et al (2004) A single infusion of brain-derived neurotrophic factor into the ventral tegmental area induces long-lasting potentiation of cocaine seeking after withdrawal. J Neurosci 24(7):1604-1611

63. Dragunow M et al (1993) Brain-derived neurotrophic factor expression after long-term potentiation. Neurosci Lett 160(2):232-236

64. da Silva Moreira, Santos A, Kelly JP, Doyle KM (2017) Dosedependent effects of binge-like methamphetamine dosing on dopamine and neurotrophin levels in rat brain. Neuropsychobiology 75(2):63-71

65. Cadet JL, Jayanthi S, Deng X (2003) Speed kills: cellular and molecular bases of methamphetamine-induced nerve terminal degeneration and neuronal apoptosis. Faseb J 17(13):1775-1788

66. Matsuzaki $\mathrm{H}$ et al (2004) Brain-derived neurotrophic factor rescues neuronal death induced by methamphetamine. Biol Psychiat 55(1):52-60

67. Bobadilla AC, Garcia-Keller C, Chareunsouk V, Hyde J, Camacho DM, Heinsbroek JA, Kalivas PW (2018) Accumbens brainderived neurotrophic factor (BDNF) transmission inhibits cocaine seeking. Addict Biol. https://doi.org/10.1111/adb.12638

68. Mao LM, Fibuch EE, Wang JQ (2010) Decoding BDNF-LTP coupling in cocaine addiction. Neuron 67(5):679-681

69. Smith DA, Browning M, Dunwiddie TV (1993) Cocaine inhibits hippocampal long-term potentiation. Brain Res 608(2):259-265

70. Soloviev A et al (2010) Electrophysiological and contractile evidence of the ability of human mesenchymal stromal cells to correct vascular malfunction in rats after ionizing irradiation. $\mathrm{J}$ Physiol Sci 60(2):161-172

71. Niwa M et al (2018) Electrophysiological properties of Ia excitation and recurrent inhibition in cat abdominal motoneurons. J Physiol Sci 6:1-10

72. Figurov A et al (1996) Regulation of synaptic responses to highfrequency stimulation and LTP by neurotrophins in the hippocampus. Nature 381(6584):706-709

73. Kang $\mathrm{H}$ et al (1997) Neurotrophins and time: different roles for TrkB signaling in hippocampal long-term potentiation. Neuron 19(3):653-664

74. Deng X et al (2001) Methamphetamine causes widespread apoptosis in the mouse brain: evidence from using an improved TUNEL histochemical method. Mol Brain Res 93(1):64-69

75. Zhu JPQ, Xu W, Angulo JA (2006) Methamphetamine-induced cell death: selective vulnerability in neuronal subpopulations of the striatum in mice. Neuroscience 140(2):607-622

Publisher's Note Springer Nature remains neutral with regard to jurisdictional claims in published maps and institutional affiliations. 